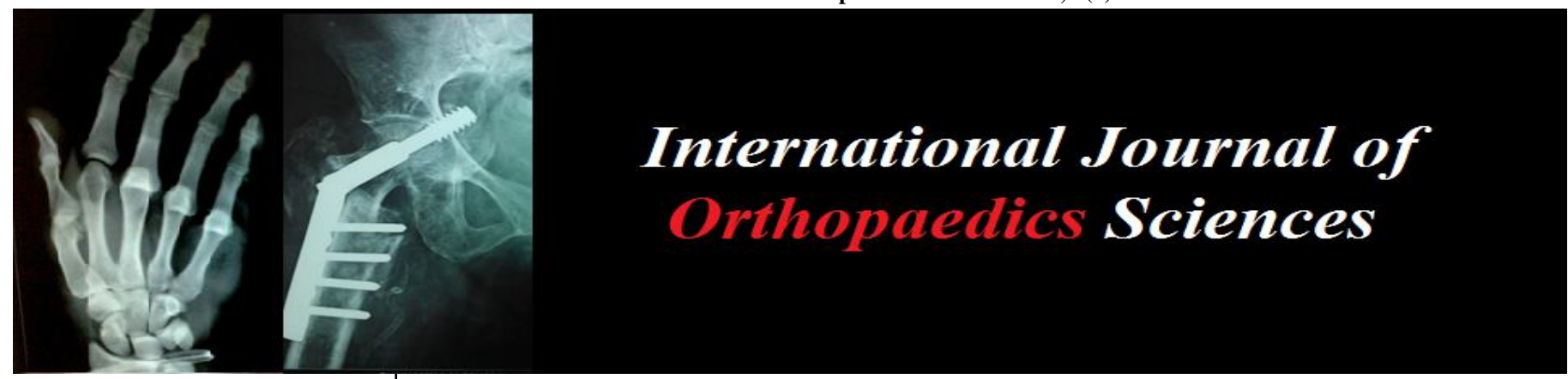

ISSN: $2395-1958$

IJOS 2018; 4(1): 952-958

(C) 2018 IJOS

www.orthopaper.com

Received: 28-11-2017

Accepted: 29-12-2017

Dr. Pradip Kumar Merli

Assistant Professor, Department of Orthopaedics, VSS Institute of

Medical Sciences and Research,

Sambalpur, Odisha, India

Dr. Rashmi Ranjan Dash Junior Resident, Department of Orthopaedics, VSS Institute of Medical Sciences and Research, Sambalpur, Odisha, India
Correspondence

Dr. Pradip Kumar Merli

Assistant Professor, Department of Orthopaedics, VSS Institute of Medical Sciences and Research, Sambalpur, Odisha, India

\section{The role of entry point and correct reduction in post- operative outcome of intertrochanteric femur fractures treated by short and long proximal femoral nails}

\author{
Dr. Pradip Kumar Merli and Dr. Rashmi Ranjan Dash
}

DOI: $\underline{\text { https://doi.org/10.22271/ortho.2018.v4.i1n.138 }}$

\section{Abstract}

Introduction: This study was performed in the department of orthopaedics, VIMSAR, Burla between July 2015 and June 2017 for evaluation of outcome of the surgical treatment of patients with intertrochanteric fracture treated with short and long proximal femoral nail and determine the role of entry point, fracture reduction in relation to neck shaft angle in treatment outcome in these patients.

Materials and Methods: All the patients with intertrochanteric fractures treated by short and long proximal femoral nails were retrospectively analysed. Out of 260 patients, 160 patients matched our inclusion criteria. Among these 160 patients, the number of patients treated by short proximal femoral nails was 100 and those treated with long proximal femoral nails was 60. Comparative evaluation of relevant patient variables, operation related variables, Post-operative outcome in terms of radiological and functional evaluation and fracture reduction in relation to neck shaft angle were carried out.

Results: We have got some unique results. Taking into consideration of parameters like AO classification, injury to surgery interval, Post-operative hospital stay, Mean time to fracture union, postoperative complications including re-fractures, postoperative outcomes in terms of rehabilitation and gaining full function, there was no significant difference between short and long PFN groups. But time taken for surgery, intraoperative blood loss and requirement for transfusion were greater in treatment with long proximal femoral nail. In comparison, Short proximal femoral nail group showed more postoperative pain and increased need for walking aids. Patients in whom quality of bone was good, correct entry point during nail insertion was made and neck shaft angle was maintained during pre-operative and intra operative period, treatment outcome was excellent irrespective of the length of the nail.

Conclusion: The long and short proximal femoral nails both are equally effective in treatment of intertrochanteric femur fractures but choice of nail should be based on skill, expertise and experience of the surgeon. Most importantly the quality of bone, operative reduction in relation to neck shaft angle and correct entry point in both long and short proximal femoral nail guide the treatment outcome maximally irrespective of the nail length.

Keywords: intertrochanteric fractures, proximal femoral nail, neck shaft angle, entry point

\section{Introduction}

The intertrochanteric fractures are very common fractures in old age people and they offer great degree of challenges with regards to management, post-operative care and rehabilitation. The rise in the incidence of intertrochanteric fractures is because of the increase in osteoporosis with age advancement. These fractures often lead to significant morbidity, mortality, and compromise in quality of life ${ }^{[1,2]}$. Post-operative mortality had been reported to be as high as $20 \%-30 \%$ in the first $6-12$ months after surgical fixation of these fractures ${ }^{[13]}$. For the management of intertrochanteric femur fractures, now the trend is towards use of intramedullary devices, as they provide better biomechanical environment. They have short lever arm, so the rotational torque and collapse at fracture site are less which is responsible for stable medial cortex and it facilitate indirect healing of fracture. Early rehabilitation and weight bearing of the fractured extremity is possible because of intramedullary nails [17]. Biomechanically, very large force is required to produce the medial migration of femoral shaft with intramedullary device, which is a common complication of extra-medullary devices ${ }^{[18]}$. The use of intramedullary devices may allow a faster restoration of postoperative walking ability, when compared with extra-medullary sliding devices ${ }^{[19,20]}$. 
It is already proved that intramedullary nails are better than extra-medullary devices but there is still existence of a dispute regarding outcome of treatment by long and short nails. Short nails have shown good biomechanical stability and acceptable clinical outcomes for the treatment of these fractures $[4,7]$. However, some evidence exists that the use of short intramedullary nails leads to a stress riser at the tip of the nail, thus predisposing patients to re-fractures around implant $[8,9$, 12]. Usually intertrochanteric fractures in the elderly population are the end result of pathologic osteoporotic or osteopenic bone, thus they require the full protection and for that to happen, longer intramedullary devices may be required. Therefore, more morbidity because of increased operative time, technical difficulty, and blood loss can be put to less importance as compared to decreased postoperative refractures around the implant. In this study, we compared the results of Long PFN and Short PFN with regard to pain, walking ability, postoperative complications, and Harris Hip Score and tried to establish other factors like quality of bone, operative reduction in relation to neck shaft angle and correct entry point for PFN insertion as major factors $\mathrm{n}$ in fact more important than nail length for better outcomes in postoperative evaluation.

\section{Materials and Methods}

This retrospective study was carried out in the department of orthopaedics of Veer Surendra Sai institute of Medical sciences and research. Patients admitted and operated for inter trochanteric femoral fractures with either Short PFN or Long PFN (Sharma, India) from July 2015 to June 2017 were reviewed with minimum 1 year of postoperative follow-up in a retrospective manner.

\section{Inclusion Criteria}

1. Patients with intertrochanteric fracture coming under $\mathrm{AO}$ classification $31-\mathrm{A} 1$ or $31-\mathrm{A} 2$

2. Patients available for at least 1 year of follow up after surgery

\section{Exclusion Criteria}

1. All patients with any pathological cause for the fracture and open fractures

2. All patients with age $<50$ years

3. All patients with multiple limb fractures

4. Patients not fit for surgery

Retrospective data was gathered from Main operation theatre record book regarding the type of PFN used. Utilising that data, post-operative notes of patients in their bed head tickets were retrieved from central record room. In a total of 160 patients, surgery for intertrochanteric fracture using short or long PFN was done between July 2015 and June 2017. These 160 patients where a minimum of 1 year of postoperative follow-up available, were retrospectively studied for pain, various complications, postoperative ability to walk, need for revision surgery and Harris Hip Score. Post-operative notes were studied for approximate blood loss and time required for surgery. Patient Bed head tickets were reviewed for age of patients, gender, injury to surgery time, duration of stay in hospital and patient condition at time of discharge.

Patient with inter trochanteric femoral fracture was admitted, and X-Ray of antero-posterior view and traction view of injured extremity was taken. All preoperative radiographs were reviewed by an orthopaedic junior Resident doctor and a senior orthopaedic consultant. Fracture is classified according to AO classification ${ }^{24}$. Below knee skin traction is applied on injured extremity with weight maximum up to $3 \mathrm{~kg}$ on Bohler Braun splint. Age, sex, side, mode of trauma, and injury to operation time span were recorded.

As the general condition of patients improved and they became fit for surgery, they were posted for surgery. Antibiotics belonging to the $2^{\text {nd }}$ generation cephalosporin group were administered 30 minutes prior to the incision and two doses were repeated post-surgery. Macrolide or Quinolone group of antibiotics were used if patients were found to be allergic to Cephalosporins. Patients were anaesthetized using Spinal anaesthesia in most of the cases.

In our study, majority of surgeries were performed by the Senior Consultant Orthopaedic surgeon, while some were performed by junior residents under direct supervision of the consultant. Keeping the patient in the supine position on a fracture table and using fluoroscopic guided imaging, all the operative procedures were carried out. After the patient was anesthetized, close reduction to near normal anatomical position was done and checked under C-ARM fluoroscopic imaging. Use of short or long nail was decided according to the surgeon's preference intra-operatively.

We always preferred entry point medial to the tip of greater trochanter in all cases. Hand reamers were used for reaming the femur and a guide wire was used in all procedures. All nails had placement of distal interlocking screws as per surgeon preference, either through the zig for short nails or by intraoperative fluoroscopic guidance for long nails. We gave maximum importance to correct fracture reduction and maintenance of neck shaft angle during our operative procedure. We didn't encounter any complications during the surgeries. Weight bearing was started according to individual patient's tolerance postoperatively.

All patients were followed up at post-operative day, 1 month, 3 month, 6 months and 12 months after the surgery. Postoperative radiographs were taken at each follow up and compared with other post-operative images. Status of fracture union was recorded during every follow up. Almost all patients achieved radiological union by 12 months after surgery. It was observed that, all implants used in the short PFN group had a length of $240 \mathrm{~mm}$ but different diameters of $9 \mathrm{~mm}, 10 \mathrm{~mm}$ and $11 \mathrm{~mm}$ were used (Figure 1, PIE CHART 1). But In the long PFN group, implants of different length and diameter were used (Figure 2, PIE CHART 2).

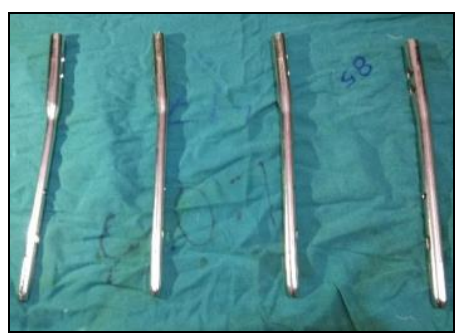

Fig 1: Short PFNs all of same length but of different diameters

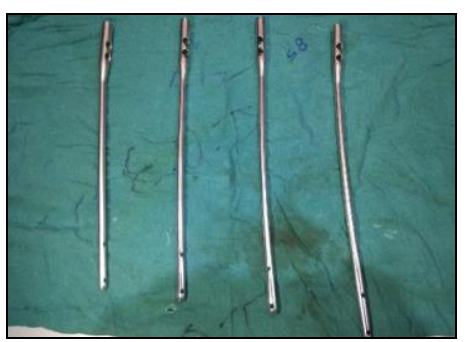

Fig 2: Long PFNs of different lengths and diameters 


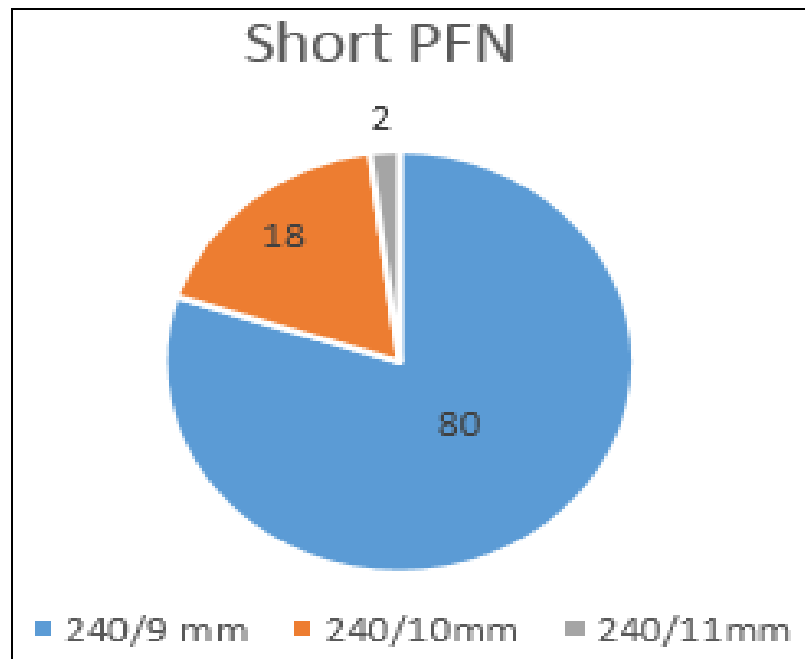

Pie Chart 1: Dimensions of Short PFN

Statistical analyses were conducted using Microsoft Excel 2016 version. Student's t test and Pearson's chi-square test were used to compare groups with categorical variables. A probability ( $\mathrm{p}$ value) of $<0.05$ was taken to be statistically significant.

\section{Results}

160 patients of intertrochanteric fractures were treated by long or short PFN between JULY 2015 and JUNE 2017. There were 100 patients in short PFN and 60 Patients in long PFN groups. There were 46 males and 54 females in short PFN group whereas 21 males 39 females in long PFN groups, so in

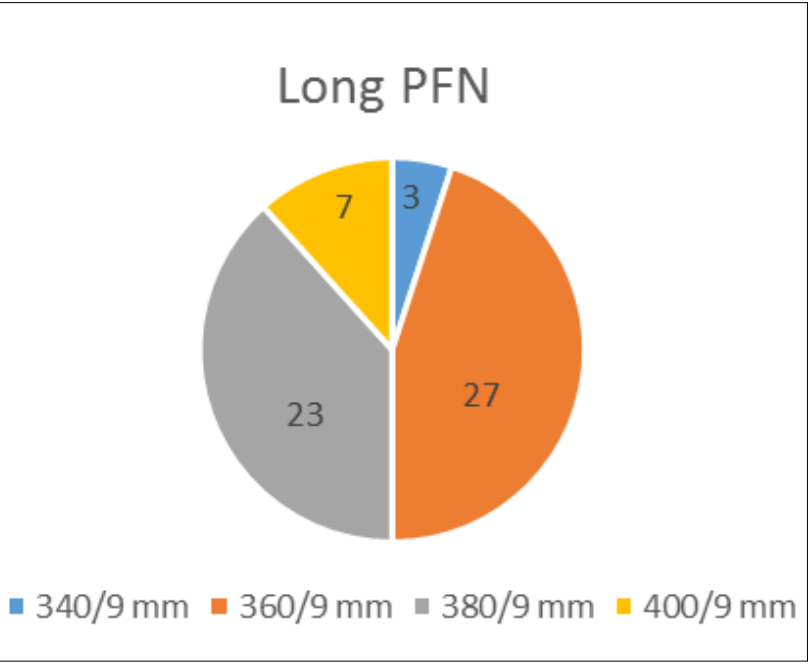

Pie Chart 2: Dimesions of Long PFN

both groups, there were higher number of females.

For the short PFN group, mean age was 62 years (range: 5177 years) and 64 years (range: 50-78 years) for the long PFN group. There were thirty three $31-\mathrm{A} 1$ and sixty seven $31-\mathrm{A} 2$ fractures in short PFN group whereas twenty eight 31-A1 and thirty two 31-A2 fracture types in long PFN group, the $p$ value $=0.284$ which was not significant so there was no significant difference in AO classification fracture types 31A2 type common among both groups. Most patients in both groups were operated upon within 3-7 days of sustaining the injury. (Table 1).

Table 1

\begin{tabular}{|c|c|c|c|}
\hline Groups & Short PFN(n=100) & Long PFN(n=60) & P value \\
\hline Sample size & 100 & 60 & \\
\hline Gender(M/F) & $46 / 54$ & $21 / 39$ & 0.224 \\
\hline Age & $64.1+/-13.1$ & $65.1+/-14.7$ & 0.200 \\
\hline Location(R/L) & $42 / 48$ & $28 / 32$ & 0.284 \\
\hline Fracture type 31-A1/A2 & $33 / 67$ & $22 / 38$ & 0.206 \\
\hline
\end{tabular}

Important patient variables between short and long PFN groups

The preoperative haemoglobin was not significantly different between the short (10.5-12.5) and the long (10.79-12.56) nail $(\mathrm{P}=0.463)$. The amount of blood loss during surgery was greater in the long PFN group $(360 \mathrm{ml}+/-120 \mathrm{ml}$ vs. $160 \mathrm{ml}$ $+/-150 \mathrm{ml}), \mathrm{p}=0.035)$. However the operative procedure lasted for 62 minutes (range: 44-80 minutes) in the short PFN group as compared to 88 minutes (range: $56-118$ minutes) in the long PFN group $(\mathrm{p}=0.026)$ which was significant (Table 2).

Table 2

\begin{tabular}{|c|c|c|c|}
\hline Variables & Short PFN(n=100) & Long PFN(n=60) & P value \\
\hline Intra-operative blood loss $(\mathrm{ml})$ Mean +/- SD & $160+/-150$ & $360+/-120$ & 0.035 \\
\hline Duration of surgery Mean +/- SD & $62+/-16$ & $88+/-32$ & 0.026 \\
\hline Time of fracture union & $10.39+/-1.12$ & $10.88+/-1.26$ & 0.093 \\
\hline Harris Hip Score at 1 year post op & $79.98+/-8.90$ & $76.16+/-10.84$ & 0.280 \\
\hline Failure rate $(\%)$ & $6(6 \%)$ & $3(5 \%)$ & 0.356 \\
\hline Hip pain $(\%)$ & $3(3 \%)$ & $0(0 \%)$ & 0.024 \\
\hline
\end{tabular}

Comparison between operations related variables in two groups

No significant difference was observed in post-operative sequelae of both short and long PFN groups. Blood transfusions during surgery was required in 12 patients in the long PFN group as compared to 4 in short PFN ( $\mathrm{p}=0.021)$ so there was a significant difference in blood transfusion requirement with long $\mathrm{PFN}$ group requiring more blood transfusion. 3 patients of long PFN group required reoperation compared to 6 in short PFN group $(\mathrm{p}=0.556)$. The mean hospital stay for both groups was almost identical with approximately 12 days for each group. No case of infection, wound dehiscence or any incision site complication were observed during hospital stay. All patients were discharged 
once stitch was removed and adequate physiotherapy instructions given to them $\mathrm{n}$ practised under supervision of the resident.

Post-op x ray during follow-up was analysed and neck shaft angle, entry point for nail insertion were evaluated. Only 2 cases of $Z$ effect were found in a short PFN Group patient and no case of reverse $Z$ effect was found either in Short PFN or Long PFN group in our study. Femoral shaft fractures, distal to the tip or around the distal part of nail, were encountered only in 1 patient. That patient in long PFN group who presented with re-fracture who met inclusion criteria, yielding an overall incidence of $0.625 \%$.That patient had re-fracture occurring at the distal end of nail 8.4 months post-operatively. Mechanism of this new injury was due to second trauma to the same limb. That re-fracture was treated with a distal femoral locking plate. More number of implant removals, due to anterior thigh pain and revision surgeries for non-union, were needed in short PFN group (6/100) than in Long PFN group (3/60) with $\mathrm{p}$ value $=0.556$ so the difference was not significant.

Even at final follow-up, only 3 patients from short PFN group (3/100) had anterior thigh pain and these might be due to impingement of distal nail tip to the anterior femoral cortex and loosening of distal interlocking bolts but no patient in long PFN group had anterior thigh pain $(p=0.024)$. Number of patients who needed walking aid were 34 in Short PFN group (34/100) than 20 in Long PFN group (20/60) with p value $=0.558$ so there was a significant difference in incidence of anterior thigh pain but no significant difference in requirement of walking aid with short PFN group patients. Mean value of Harris hip score in short PFN group was 79 (range 70-87) and 77 in long PFN group (range 68-88) with $p$ value $=0.280$ so there was no significant difference in Harris Hip Score between Long PFN group and Short PFN group at 1 year follow up. (Table 2)

All patients were followed up for at least one year.8 patients $(13.33 \%)$ in the long PFN group and 12 patients $(12 \%)$ in the short PFN group had died within one year of undergoing the surgery $(p=0.446)$.Difference in mortality associated with short and long PFN was not significant.

\section{Discussion}

Fractures of intertrochanteric femur has been come across as the ultimate challenge to Orthopaedic surgeons, not solely for achieving fractures union, but for restoration of optimal function in the shortest possible time that to with minimal complications. The aim of management accordingly has shifted to aim for early mobilization, rapid rehabilitation and quick return of individuals to premorbid home and work environment as a functionally and psychologically independent unit. Operative treatment in the form of internal fixation permits early rehabilitation and offers the best chance of functional recovery, and hence has become the treatment of choice for virtually all fractures in the trochanteric region. Worldwide literatures now support intramedullary implants as better implants than extra-medullary implants in management of intertrochanteric fractures. Intramedullary implants commonly used are Gamma nails and Proximal Femoral Nails. Although they are better than conventional DHS and DCS, still they carry variable rate of complications in form of anterior thigh pain, femoral shaft fractures distal or around the tip of implant, more revision surgeries and finally decreased walking ability.

Now PFN has evolved into use more largely. It comes in 2 types as long and short PFN. According to our study, the use of a short nail significantly decreased duration of surgery, blood loss during surgery and need for transfusion which is evident from our results. There was no significant difference in the duration of stay in hospital between the long and the short nail groups. Difference in rate of Re-operation related to surgical complications between the long nail and the short nail groups wasn't significant. The re-fracture rate around these implants was extremely low $(0.625 \%$ in our study population) and with the use of long nail, re-fracture wasn't totally avoided. Previous literature has found re-fracture rates of new implants to be ranging from $0.6 \%$ to $1.7 \%$. ${ }^{[13,14,15,16]}$. The rate of re-fracture for short intramedullary nails has been observed to be in range from $0 \%$ to $20 \% .{ }^{[5,10,14]}$. However, a review of the literature showed re-fracture distal to short intramedullary nails has decreased significantly with new generations of implants ${ }^{[14,16]}$. Long nails used to treat a various femur fractures have been reported with low rates of fracture around or distal to these implants ${ }^{[16,32]}$. Norris et al. ${ }^{[16]}$ found that fractures around longer implants has lower risk compared with short implants, although this finding was not statistically significant.

The correct technique of PFN insertion is most important. Entry point medial to the tip of greater trochanter was chosen by us during surgery to avoid varus reduction and to maintain neck shaft angle. Hwang et al. had written some points regarding better implant insertion ${ }^{[32]}$. The ethnic background must be considered during implant insertion like Asian population with relatively short femur. An excessive anterior bowing in a relatively shorter femur need careful evaluation and precise choice of entry point ${ }^{[33]}$. Old patients with significant osteoarthritis, longer nails may be preferred as the entry point is more anatomically aligned as compared to the short nails. Usually surgeon should refrain from hammering the nail in, however gentle hammering process may be done in long PFN.

$\mathrm{Z}$ effect and reverse $\mathrm{Z}$ effect in the treatment of inter trochanteric fractures are well kown complications [21-23, 25]. Eccentrically placed lag screws cause both rotational cut out and Varus collapse which may lead to $\mathrm{z}$ effect and reverse $\mathrm{z}$ effect. In approximately $12 \%$ of intertrochanteric fractures, progressive rotation occurs as they collapse and rotation has been shown to more common in cases with lag screw cut out $[26,27]$. One of the studies done in European clinics on the efficacy of PFN ${ }^{[23]}$, found PFN to be the ideal implant in the treatment of unstable pertrochanteric fractures with advantage of lesser incidence of femoral head penetration by the screw. In our study We Stressed on preoperative and intra-operative correct reduction and maintenance of neck shaft angle between 160-180 degrees checked under C-ARM guidance in both AP and Lateral view (figure 3-6). but only in 3 patients neck shaft angle was $<150$ degrees in post-op X-ray analysed during follow up. That may be the reason, there were no cases of lag screw cut out and 2 cases of z-effect (figure 7) due to varus reduction which was determined in follow up by analysing post-op $\mathrm{x}$-ray showing neck shaft angle $<150$ degree and severe osteoporotic bone but there was no case of reverse $\mathrm{z}$-effect in our follow up patients. 


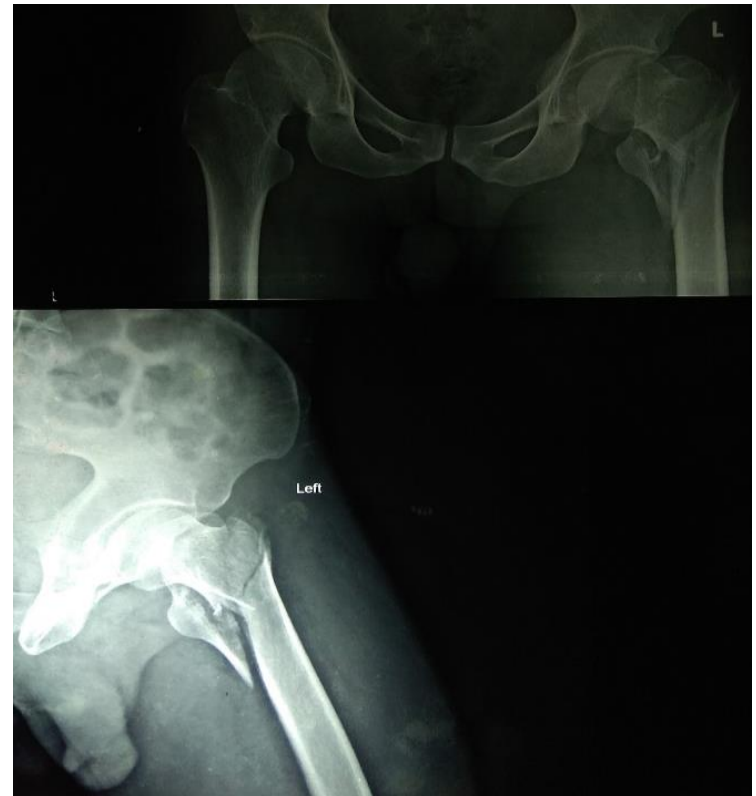

Fig 3: pre-operative $\mathrm{x}$ ray AP and Lateral views of fracture intertrochanteric femur

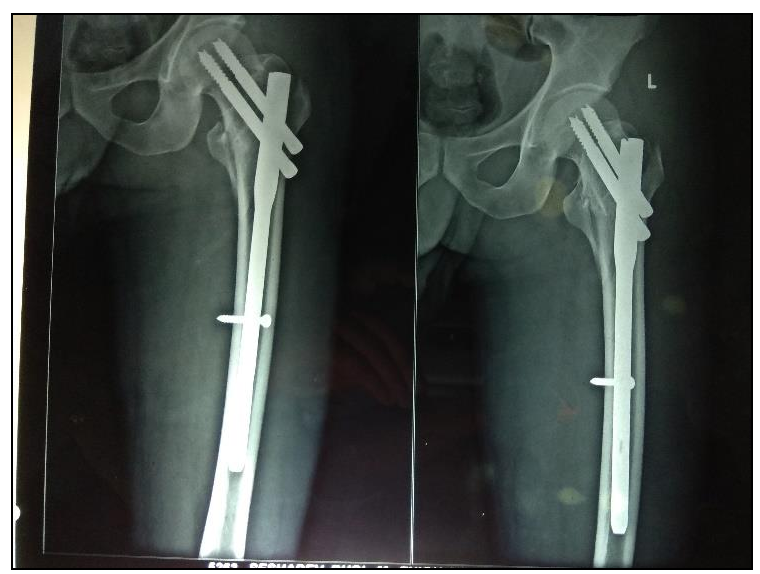

Fig 4: Immediate post op x-ray with entry point medial to the tip of Greater trochanter and Maintained neck shaft angle

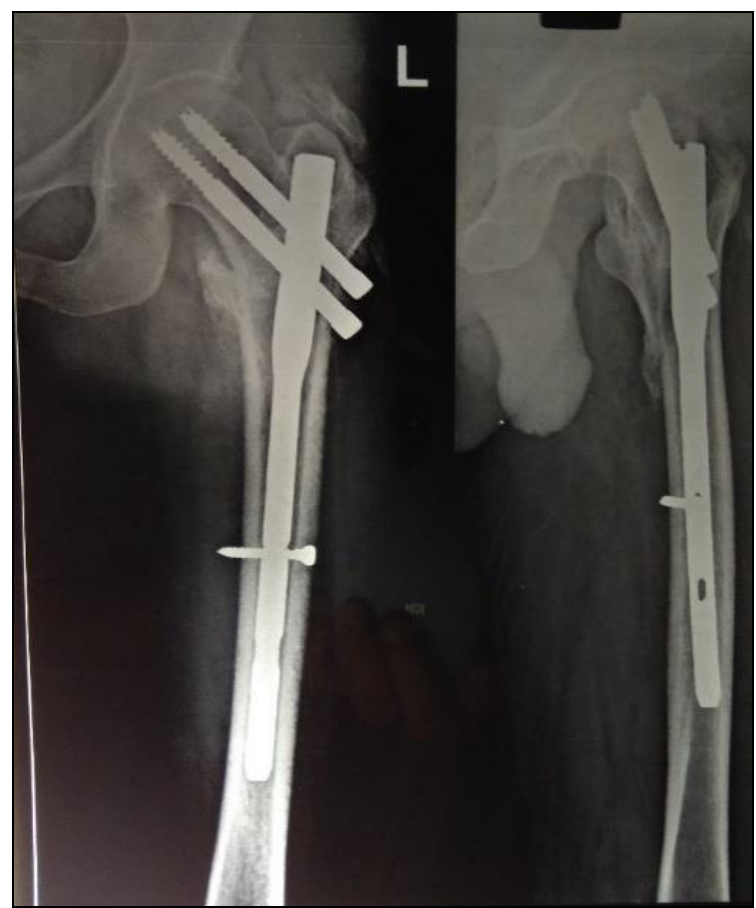

Fig 5: Follow up x ray showing callus formation at 3 months

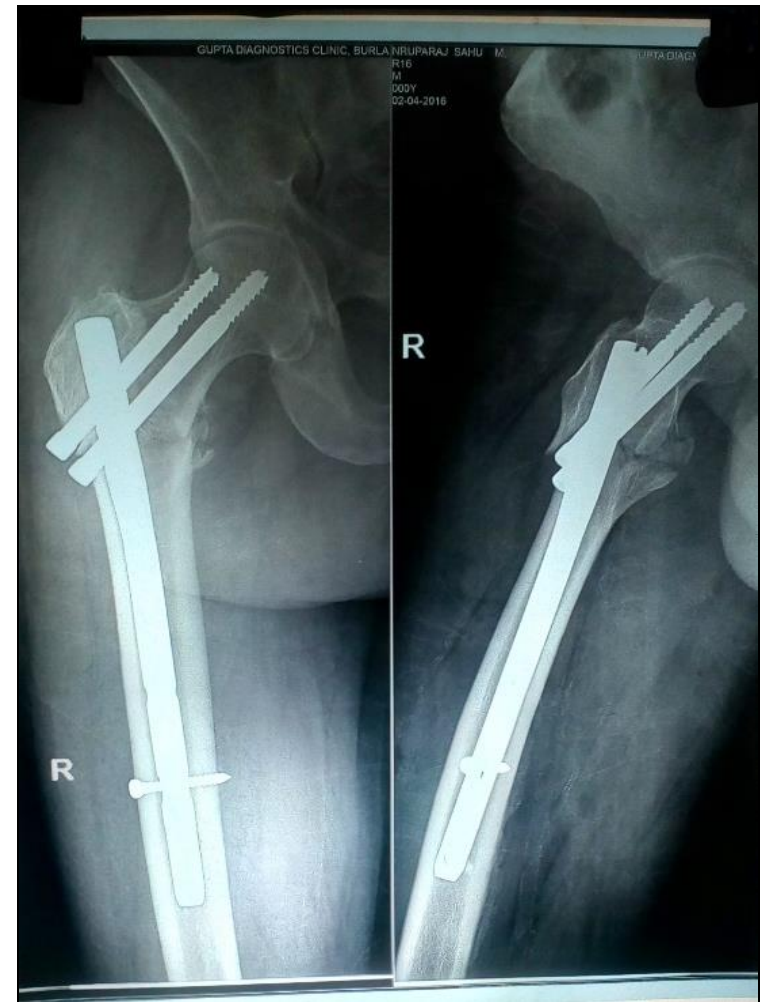

Fig 6: Another post op x ray with maintained neck shaft angle and correct entry point

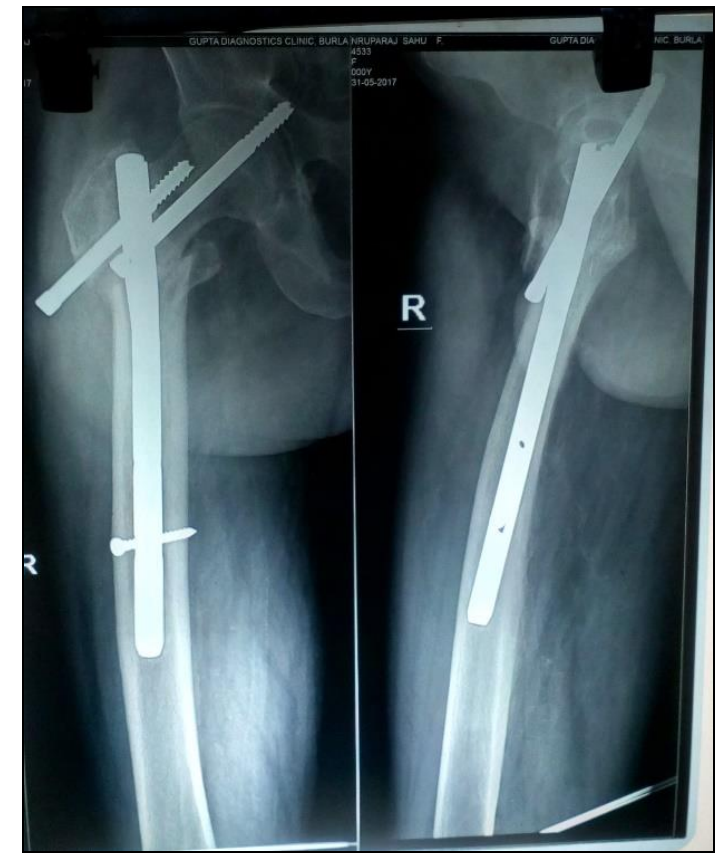

Fig 7: Effect in a short PFN Group patient

Bone mineral density (BMD) of the trochanteric region obtained in DEXA scan is the best indicator for predicting pertrochanteric fractures ${ }^{[28]}$. The highest concentration of stress is usually at the lag screw hole of the intramedullary implant ${ }^{[28]}$. The angle of insertion of a nail during surgery is a very important factor because stress on nail and bone distal to tip of nail depends on the angle of insertion ${ }^{[29]}$. So choosing the entry point for nail insertion medial to tip of greater trochanter keeping in view anterior bow of femur probable led to very few failure rates with both short and long PFN in our study.

All the literatures are showing decreasing and clinically 
acceptable rate of re-fracture with regard to femoral intramedullary nails ${ }^{[10-14,19-24]}$. Our study also supports the literatures. Length and anterior bowing of femur are important patient variables that guide treatment outcome. In some osteoporotic patients, insertion of long PFN may difficult due to anterior bowing. We found in our study that, short PFN and long PFN both have comparable re-fracture rates and the difference was not significant. However further studies with a more number of patients would be needed for a better evaluation to arrive at a conclusion.

Fractures around a short nail usually requires removal of nail and revision to a longer intramedullary nail, whereas a fracture around a long nail can be treated with a lateral plate and does not require removal of the original implant.so choice of implant should also be based on the revision surgery requirement with less morbidity.

However walking ability of the patients was improved remarkably in Long PFN group post operatively than in Short PFN group, as distal femur has relatively large medullary cavity which contain end of the long nail, so pressure on the femoral cortex is less and that's why postoperative pain is also less. Our study results showed that patients with entry point medial to Greater trochanter and neck shaft angle 160180 degree have better walking ability, less post-operative hip pain and better Harris hip score. (Table 2 and table 3)

Table 3: Role of entry point and neck shaft angle of femur in postoperative outcome

\begin{tabular}{|c|c|c|}
\hline Entry point & $\begin{array}{c}\text { Short } \\
\text { PFN(n=100) }\end{array}$ & $\begin{array}{c}\text { Long } \\
\text { PFN(n=60) }\end{array}$ \\
\hline Medial to tip of GT & $86(86 \%)$ & $55(91.66 \%)$ \\
\hline Sites other than medial to tip of GT & $14(14 \%)$ & $5(8.33 \%)$ \\
\hline \multicolumn{3}{|c|}{ Neck shaft angle } \\
\hline 160-180 degree & $80(80 \%)$ & $50(83.33 \%)$ \\
\hline 150-160 degree & $17(17 \%)$ & $10(16.66 \%)$ \\
\hline <150 degree & $3(3 \%)$ & $0(0 \%)$ \\
\hline \multicolumn{2}{|c|}{ Walking ability } \\
\hline Independent & $66(66 \%)$ & $40(66.66 \%)$ \\
\hline Aided & $34(34 \%)$ & $20(33.33 \%)$ \\
\hline Bed-ridden & $0(0 \%)$ & $0(0 \%)$ \\
\hline
\end{tabular}

\section{Conclusion}

The long and short proximal femoral nails both are equally effective in treatment of intertrochanteric femur fractures but short nail significantly decreases duration of surgery, blood loss during surgery and incidence of transfusion whereas long nail has advantage of less post-operative pain and improved walking ability of patients. However there are no significant difference in mean time to fracture union, post-operative complications including re-fractures, postoperative outcomes in terms of rehabilitation, return to previous functional level and lower extremity functionality scale.

The long and short implants both can be used interchangeably but choice of implant should be based on skill, expertise and experience of the surgeon.

Most importantly the quality of bone, operative reduction in relation to neck shaft angle and correct entry point in both long and short PFN influence the treatment outcome in a major way.

The short duration and retrospective nature are the major drawbacks of this study. However, more double blind, randomized, Prospective studies with greater statistical power and longer term follow-up need to be done to establish the findings in our study.

\section{References}

1. Brauer CA, Coca-Perraillon M, Cutler DM, et al. Incidence and mortality of hip fractures in the United States. JAMA. 2009; 302:1573-1579.

2. Tosteson AN, Gottlieb DJ, Radley DC, et al. Excess mortality following hip fracture: the role of underlying health status. Osteoporos Int. 2007; 18:1463-1472.

3. Melton LJ III, Gabriel SE, Crowson CS, et al. Costequivalence of different osteoporotic fractures. Osteoporos Int. 2003; 14:383-388.

4. Bellabarba C, Herscovici DJR, Ricci WM. Percutaneous treatment of peritrochanteric fractures using the gamma nail. J Orthop Trauma. 2003; 17:S38-S50.

5. Bellabarba C, Herscovici DJR, Ricci WM. Percutaneous treatment of peritrochanteric fractures using the Gamma nail. Clin Orthop Relat Res. 2000; 375:30-42.

6. Calvert PT. The Gamma nail—a significant advance or a passing fashion? J Bone Joint Surg Br. 1992; 74:329-331.

7. Jones HW, Johnston P, Parker M. Are short femoral nails superior to the sliding hip screw? A meta-analysis of 24 studies involving 3,279 fractures. Int. Orthop. 2006; 30:69-78.

8. Valverde JA, Alonso MG, Porro JG, et al. Use of the gamma nail in the treatment of fractures of the proximal femur. 1998. J Orthop Trauma. 2003; 17:S51-S56.

9. Lorich DG, Geller DS, Nielson JH. Osteoporotic pertrochanteric hip fractures: management and current controversies. Instr Course Lect. 2004; 53:441-454.

10. Hesse B, Gachter A. Complications following the treatment of trochanteric fractures with the gamma nail. Arch Orthop Trauma Surg. 2004; 124:692-698.

11. Radford PJ, Needoff M, Webb JK. A prospective randomised comparison of the dynamic hip screw and the gamma locking nail. J Bone Joint Surg Br. 1993; 75:789793.

12. Bridle $\mathrm{SH}$, Patel $\mathrm{AD}$, Bircher $\mathrm{M}$, et al. Fixation of intertrochanteric fractures of the femur. A randomised prospective comparison of the gamma nail and the dynamic hip screw. J Bone Joint Surg Br. 1991; 73:330334.

13. Kokoroghiannis C, Aktselis I, Deligeorgis A, et al. Evolving concepts of stability and intramedullary fixation of intertrochanteric fractures - a review. Injury. 2012; 43:686-693.

14. Bojan AJ, Beimel C, Speitling A, et al. 3066 consecutive Gamma nails. 12 years experience at a single centre. BMC Musculoskelet Disord. 2010; 11:133.

15. Menezes DF, Gamulin A, Noesberger B. Is the proximal femoral nail a suitable implant for treatment of all trochanteric fractures? Clin Orthop Relat Res. 2005; 439:221-227.

16. Norris R, Bhattacharjee D, Parker MJ. Occurrence of secondary fracture around intramedullary nails used for trochanteric hip fractures: a systematic review of 13,568 patients. Injury. 2012; 43:706-711.

17. Lindskog DM, Baumgaertner MR. Unstable intertrochanteric hip fractures in the elderly. J Am Acad Orthop Surg. 2004; 12:179-190.

18. Weil YA, Gardner MJ, Mikhail G, Pierson G, Helfet DL, Lorich DG. Medial migration of intramedullary hip fixation devices: a biomechanical analysis. Arch Orthop Trauma Surg. 2008; 128:227-234

19. Pajarinen J, Lindahl J, Michelsson O, Savolainen V, Hirvensalo E. Pertrochanteric femoral fractures treated with a dynamic hip screw or a proximal femoral nail. J 
Bone Joint Surg [Br]. 2005; 87- B:76-81.

20. Domingo LJ, Cecilia D, Herrera A, Resines C. Trochanteric fractures treated with a proximal femoral nail. Int Orthop SICOT. 2001; 25:298-301

21. Bolhofner BR, Russo PR, Carmen B. Results of intertrochanteric femur fractures treated with a 135degree sliding screw with a two-hole side plate. J Orthop Trauma. 1999; 13(1):5-8.

22. Chinoy M, Parker M. Fixed nail plates versus sliding hip systems for the treatment of trochanteric femoral fractures: a meta analysis of 14 studies. Injury. 1999; 30(3):157-63.

23. Sommers MB, Roth C, Hall H, Kam BC, Ehmke LW, Krieg JC, et al. A laboratory model to evaluate cut out resistance of implants for pertrochanteric fracture fixation. J Orthop Trauma. 2004; 18(6):361-8.

24. Baumgaertner MR, Curtin SL, Lindskog DM, Keggi JM. The value of the tip-apex distance in predicting failure of fixation of peritrochanteric fractures of the hip. J Bone Joint Surg. 1995; 77(7):1058-64.

25. Baumgaertner MR, Solberg BD. Awareness of tip-apex distance reduces failure of fixation of trochanteric fractures of the hip. J Bone Joint Surg. 1997; 79(6):96971.

26. Ehmke LW, Fitzpatrick DC, Krieg JC, Madey SM, Bottlang M. Lag screws for hip fracture fixation: Evaluation of migration resistance under simulated walking. J Orthop Res: official publication of the Orthopaedic Research Society. 2005; 23(6):1329-1335.

27. Lustenberger A, Bekic J, Ganz R. [Rotational instability of trochanteric femoral fractures secured with the dynamic hip screw. A radiologic analysis]. Der Unfallchirurg. 1995; 98(10):514-7.

28. Gebauer M, Stark O, Vettorazzi E, Grifka J, Puschel K, Amling M, et al. DXA and $\mathrm{pQCT}$ predict pertrochanteric and not femoral neck fracture load in a human sideimpact fracture model. Journal of orthopaedic research: official publication of the Orthop Res Soc. 2014; 32(1):31-38. doi:10.1002/jor.22478.

29. Eberle S, Gerber C, von Oldenburg G, Hungerer S, Augat P. Type of hip fracture determines load share in intramedullary osteosynthesis. Clin Orthop. 2009; 467(8):1972-1980.

30. Cumming RG, Nevitt MC, Cummings SR. Epidemiology of hip fractures. Epidemiologic Reviews. 1997; 19(2):244-57.

31. Pinilla T, Boardman K, Bouxsein M, Myers E, Hayes W. Impact direction from a fall influences the failure load of the proximal femur as much as age-related bone loss. Calci Tissue Internat. 1996; 58(4):231-235.

32. Hwang JH, Oh JK, Han SH, Shon WY, Oh CW. Mismatch between PFNa and medullary canal causing difficulty in nailing of the pertrochanteric fractures. Archives of orthopaedic and trauma surgery. 2008; 128(12):1443-6.

33. Tang W, Chiu K, Kwan M, Ng T, Yau W. Sagittal bowing of the distal femur in Chinese patients who require total knee arthroplasty. J Orthop Res. 2005; 23(1):41-5. 